\title{
Luftsichel sign and juxtaphrenic peak sign
}

\section{P S Sriram, Abhishek Biswas}

Department of Medicine, University of Florida, Gainesville, Florida, USA

\section{Correspondence to} Dr P S Sriram:

sriramp@medicine.ufl.edu

Accepted 23 April 2015

\section{DESCRIPTION}

A 56-year-old man presented with a 1-week history of cough, dyspnoea and left-sided chest pain. A chest radiograph revealed left mid lung infiltrates (figures 1 and 2). He was treated as an outpatient with an antibiotic for community-acquired pneumonia. His symptoms resolved and a chest X-ray 2 months later showed an elevated left hemidiaphragm with a characteristic Luftsichel sign (figures 3 and 4). A lateral view X-ray showed left upper lobe collapse with anterior displacement of the oblique fissure and elevation of the left hemidiaphragm

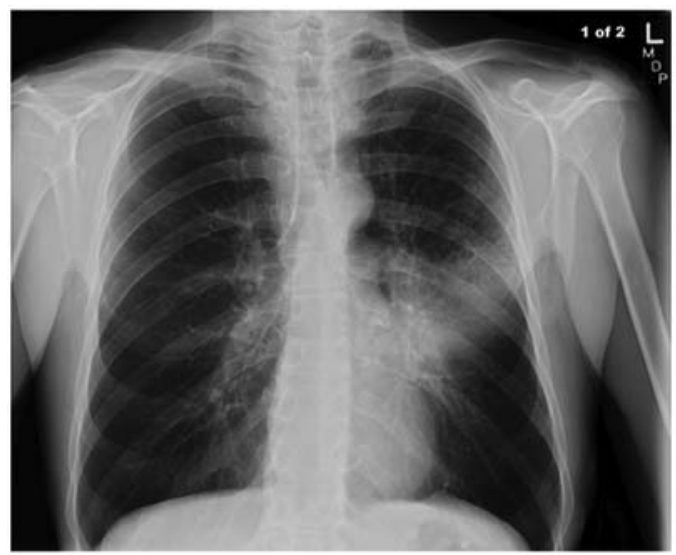

Figure 1 Chest X-ray posteroanterior showing left mid lung infiltrates.

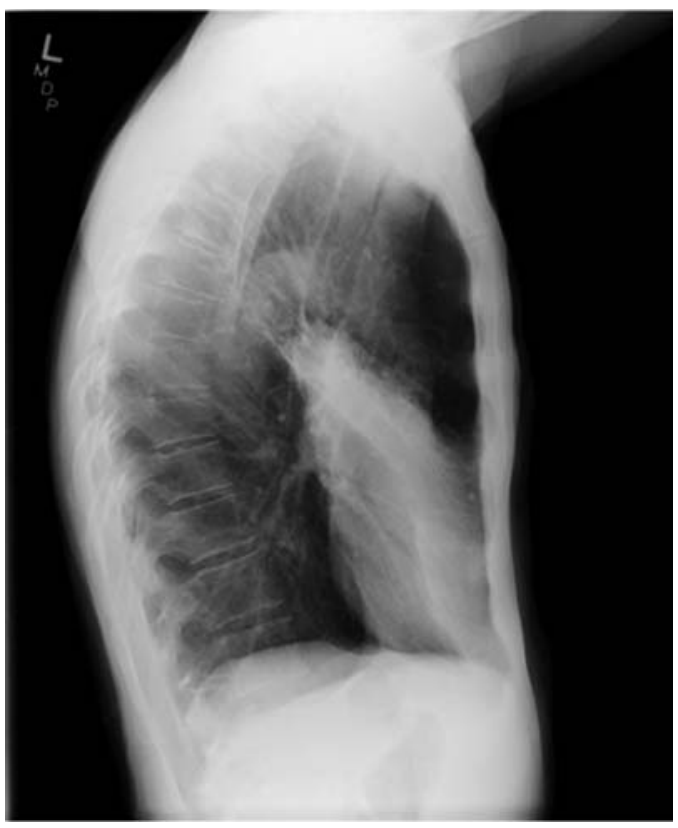

Figure 2 Chest X-ray lateral view showing left mid lung infiltrates. (figure 5). A CT of the chest confirmed left upper lobe collapse due to an endobronchial lesion (figure 6). In addition, chest X-ray showed presence of a juxtaphrenic peak sign that had become more

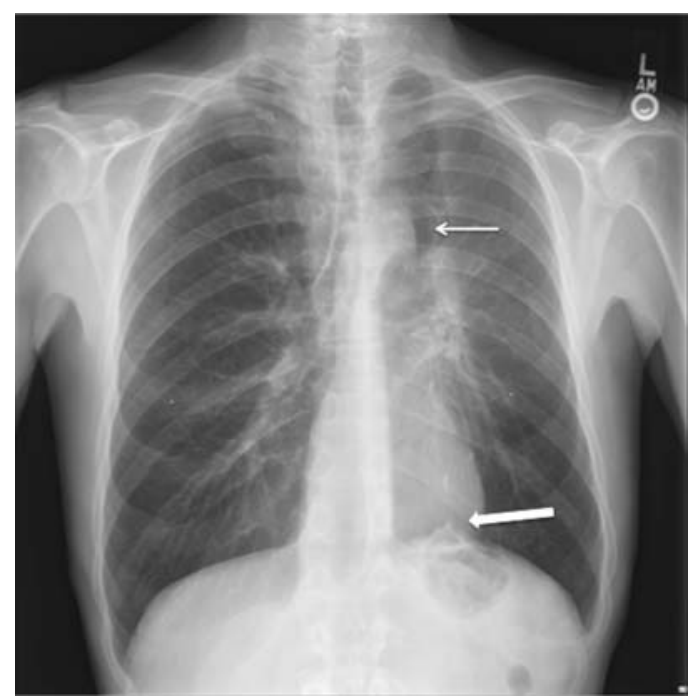

Figure 3 Chest X-ray showing a characteristic Luftsichel sign (arrow: air crescent around the aortic arch) with elevated left hemidiaphragm and a prominent left hilum. Chest X-ray also shows a peaked or tented appearing left hemidiaphragm representing the juxtaphrenic peak sign (block arrow).

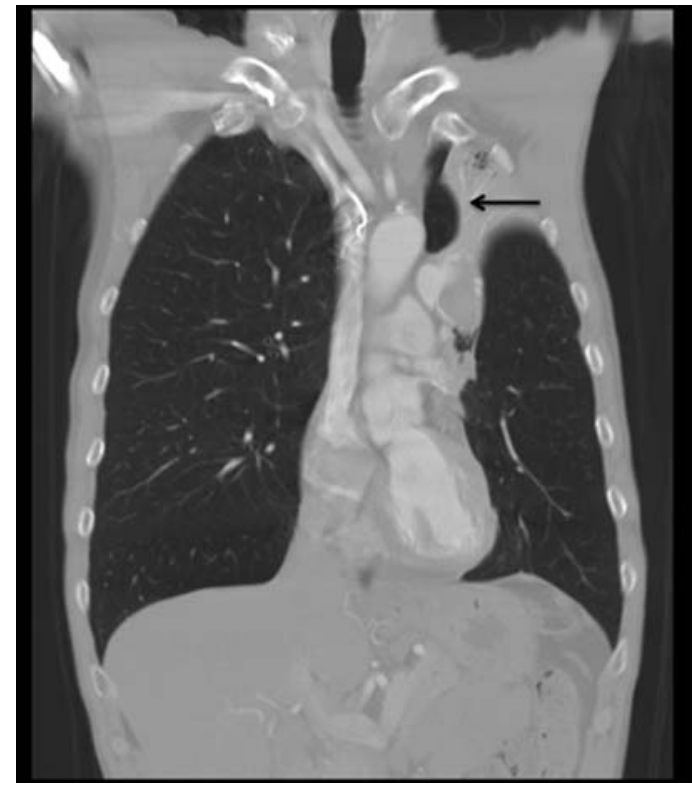

Figure 4 A CT scan showing an aerated left lower lobe juxtaposed between the aorta and a collapsed left upper lobe that results in the Luftsichel sign on chest X-ray (arrow). 


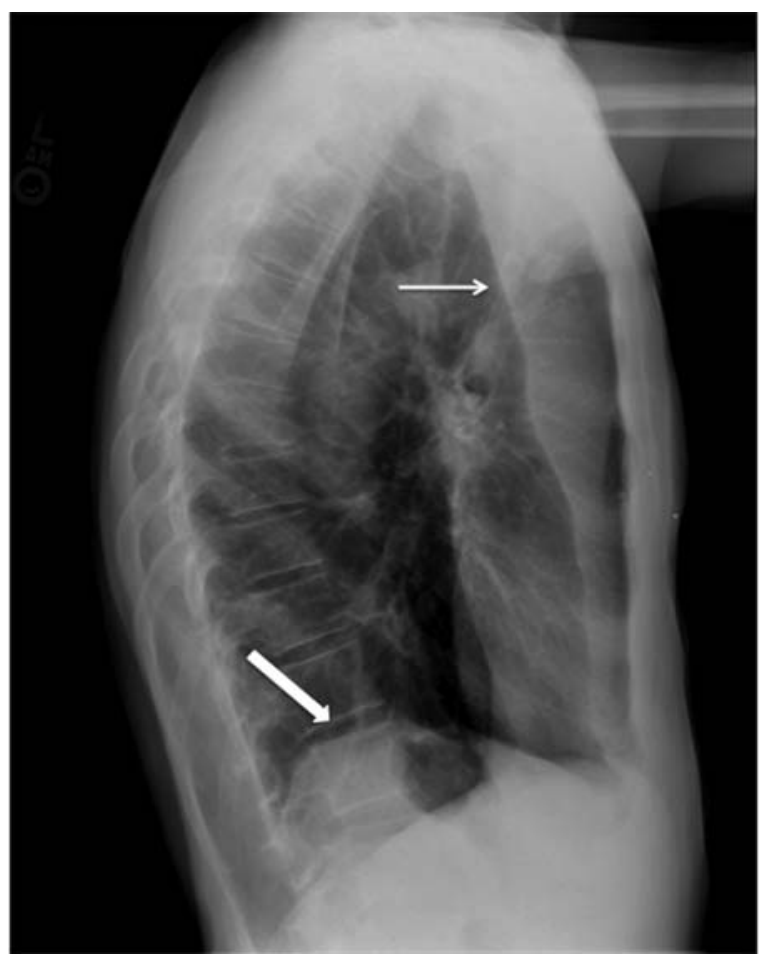

Figure 5 Lateral view X-ray showing collapse of the left upper lobe with anterior displacement of the oblique fissure (arrow) and elevation of the left hemidiaphragm (block arrow).

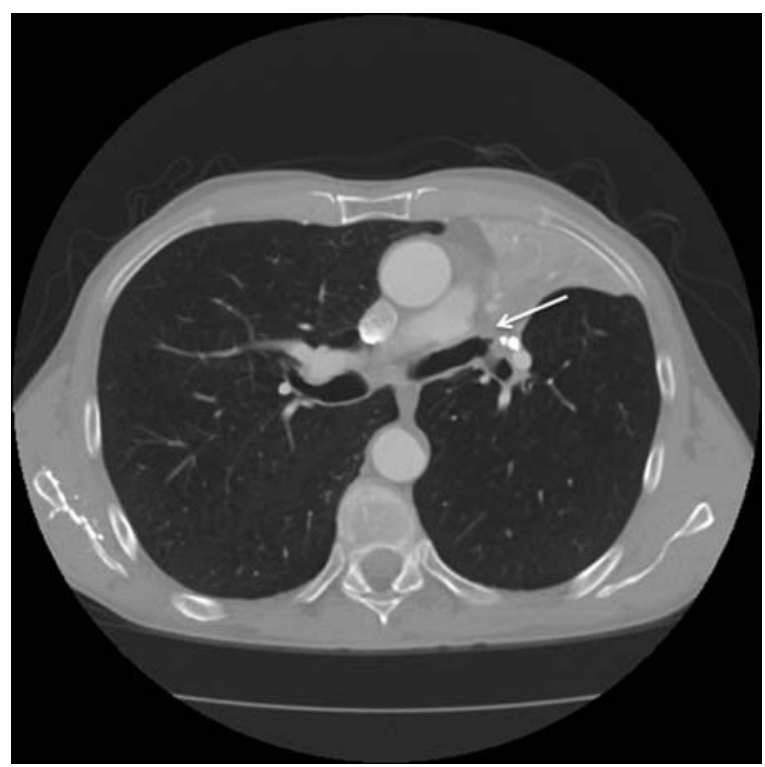

Figure 6 A CT of the chest confirms left upper lobe collapse due to an endobronchial lesion (arrow).

prominent compared to prior chest X-ray (figure 3) and was confirmed on CT of the chest (figure 7).

Luftsichel sign (in German: Luft: air and sichel: crescent) was first described in 1942. ${ }^{1}$ This sign is seen in left upper lobe

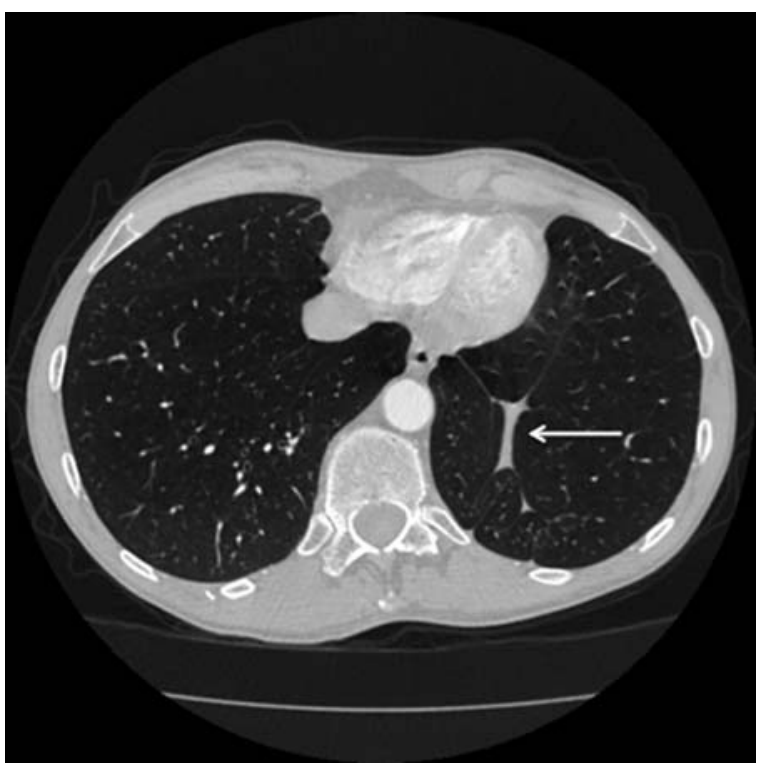

Figure $7 \mathrm{CT}$ of the chest showing a prominent inferior accessory fissure responsible for the juxtaphrenic peak sign (arrow).

collapse. When the left upper lobe collapses, the superior segment of the left lower lobe shifts upwards and anteriorly, interspersing between the aortic arch and the collapsed left upper lobe. The ensuing air crescent around the aortic arch is the Luftsichel sign. ${ }^{2}$

Juxtaphrenic peak sign has been well described in chest X-rays following upper lobe volume loss (for eg, lobectomy, tuberculosis or radiation). A prominent inferior accessory fissure is the main reason for this sign. This sign is noted to appear in $70 \%$ of patients after right upper lobectomy and in 50\% after left upper lobectomy. Presence of this sign is suggestive of upper lobe volume loss and is never seen after lower lobe lobectomy. ${ }^{3}$

\section{Learning points}

- Luftsichel (air crescent) sign is suggestive of left upper lobe collapse.

- Juxtaphrenic peak sign is seen in chest X-rays following upper lobe volume loss.

Competing interests None declared.

Patient consent Obtained.

Provenance and peer review Not commissioned; externally peer reviewed.

\section{REFERENCES}

1 Webber M, Davies P. The Luftsichel: an old sign in upper lobe collapse. Clin Radiol 1981;32:271-5.

2 Algin 0, Gokalp G, Topal U. Signs in chest imaging. Diagn Interv Radiol 2011:17:18-29.

3 Konen E, Rozenman J, Simansky DA, et al. Prevalence of the juxtaphrenic peak after upper lobectomy. AJR 2001;177:869-73. 
Copyright 2015 BMJ Publishing Group. All rights reserved. For permission to reuse any of this content visit http://group.bmj.com/group/rights-licensing/permissions.

BMJ Case Report Fellows may re-use this article for personal use and teaching without any further permission.

Become a Fellow of BMJ Case Reports today and you can:

- Submit as many cases as you like

- Enjoy fast sympathetic peer review and rapid publication of accepted articles

- Access all the published articles

- Re-use any of the published material for personal use and teaching without further permission

For information on Institutional Fellowships contact consortiasales@bmjgroup.com

Visit casereports.bmj.com for more articles like this and to become a Fellow 